\title{
Questes
}

\section{Secret, public, privé : éléments bibliographiques}

\section{Clémence Revest}

\section{(2) OpenEdition}

\section{Journals}

\section{Édition électronique}

URL: https://journals.openedition.org/questes/810

DOI : $10.4000 /$ questes. 810

ISSN : 2109-9472

\section{Éditeur}

Les Amis de Questes

\section{Édition imprimée}

Date de publication : 15 avril 2009

Pagination : 87-91

ISSN : 2102-7188

\section{Référence électronique}

Clémence Revest, «Secret, public, privé : éléments bibliographiques », Questes [En ligne], 16 | 2009,

mis en ligne le 01 janvier 2014, consulté le 28 juin 2022. URL : http://journals.openedition.org/ questes/810 ; DOI : https://doi.org/10.4000/questes.810 


\section{Éléments bibliographiques}

\section{Définitions et usages des concepts}

BoK, Sissela, Secrets. On the Ethics of Concealment and Revelation, New York, Pantheon Books, 1982.

BoutAng, Pierre, Ontologie du Secret, Paris, PUF, Quadrige, 1973.

BRUNEL, Pierre, L'Imaginaire du secret, Grenoble, Ellug, 1998.

Du secret, Nouvelle revue de psychanalyse, 14 (automne 1976).

HABERMAS, Jürgen, L'Espace public. Archéologie de la publicité comme dimension constitutive de la société bourgeoise, trad. fr., Paris, Payot, 1978.

Maurey, Gilbert, Secret, secrets : de l'intime au collectif, Bruxelles-Paris, De Boeck université, 1999.

Petitat, André (dir.), Secret et lien social, Paris, L’Harmattan, 2000.

POPPER, Karl Raimund, The Open Society and its Ennemies, London, G. Routledge and sons, 1945, 2 vol.

TefFT, Stanton K. (dir.), Secrecy : a cross-cultural perspective, New York, Human Sciences Press, 1980.

TRIPET, Arnaud, Poétique du secret, Paris, Champion, 2007.

WuiLleme, Tanguy (dir.), Autour des secrets, Paris, L'Harmattan, 2004. 


\section{Secret et littérature}

Brunet, Éliane, Bouvier, Pascal, Lenoir-Belloc, Catherine (dir.), Sémiologie du secret, représentations du secret et de l'intime dans les arts et la littérature, Malissard, éditions Aleph, 2004.

Floris, Ubaldo, VIRDIS, Maurizio (dir.), Il Segreto. Atti del Convegno di studi, Cagliari 1-4 aprile 1999, Rome, Bulzoni, 2000.

ZABus, Chantal (dir.), Le Secret : motif et moteur de la littérature, Louvain-laNeuve, Collège Érasme, 1999.

\section{Le secret dans la littérature courtoise médiévale : quelques études spécifiques}

BRAULT, Jacques, «Le secret d'amour dans la lyrique courtoise », dans Bruno RoY (dir.), L’Érotisme au Moyen Âge: études présentées au troisième colloque de l'Institut d'études médiévales de l'Université de Montréal, [3-4 avril 1976], Montréal, éd. de l'Aurore, 1977.

Gutierrez Garcia, Santiago, et Souto Espasandin, Monica, « Le senhal occitan et le secret de la dame en gallicien-portugais », Revue des langues romanes, 107/2 (2003), p. 411-428.

LE NAN, Frédérique, Le Secret dans littérature narrative arthurienne (11501250). Du lexique au motif, Paris, Champion, 2002.

MACPHERSON, Ian, «Secret language in the Cancioneros: some courtly codes », Bulletin of Hispanic Studies, 62/1 (1985), p. 51-63.

SPEARING, Anthony Colin, The Medieval Poet as Voyeur: Looking and Listening in Medieval Love- Narratives, Cambridge, New York, Cambridge University Press, 1993. 


\section{Histoire et secret}

ArIES, Philippe, Duby, Georges (dir.), Histoire de la vie privée, 5 t., Paris, Seuil, 1985-1987.

LOCHRIE, Karma, Covert operations. The medieval uses of secrecy, Philadelphie, University of Pennsylvania Press, 1999.

Il Segreto. Micrologus. Natura, Scienze e Società Medievali, XIV (2006).

Tilloy, Michèle, Audisio, Gabriel et Chiffoleau, Jacques (dir.), Histoire et clandestinité du Moyen Age à la Première Guerre mondiale, Actes du Colloque de Privas, mai 1977, Albi, Ateliers professionnels de l'O. S. J., 1979.

\section{Diffusion et contrôle de l'information}

Boudreau, Claire, FiAnu, Kouky, Gauvard, Claude et Hebert, Michel (dir.), Information et société en Occident à la fin du Moyen Âge, Actes du colloque international tenu à l'Université du Québec à Montréal et à l'Université d'Ottawa (9-11 mai 2002), Paris, Publications de la Sorbonne, 2004.

EPSTEIN, Steven, «Secrecy and Genoese Commercial Practices », Journal of Medieval History, 20, nº 4 (1994), p. 313-326.

JONES-DAVIES, Marie-Thérèse (dir.), Rumeurs et nouvelles au temps de la Renaissance, Actes des colloques des 13-14 décembre 1996 et 21-22 mars 1997, Paris, Klincksieck, 1997.

La Circulation des nouvelles au Moyen Âge, XXIV Congrès de la SHMES (Avignon, juin 1993), Paris-Rome, Publications de la Sorbonne, 1994.

NovaK, Veronika, Nouvelles, pouvoir et société. La circulation des informations à Paris à la fin du Moyen Âge, Budapest, Gondola-Infonia, 2007.

PARENT, Sylvain, «Publication et publicité des procès à l'époque de Jean XXII (1316-1324) : l'exemple des seigneurs gibelins italiens et de Louis de 
Bavière », Mélanges de l'École Française de Rome - Moyen Âge, 119-1 (2007), p. 93-134.

\section{Le secret d'état}

DEWERPE, Alain, Espion. Une anthropologie historique du secret d'État contemporain, Paris, Gallimard, 1994.

KANTOROWICZ, Ernst, «Mystères de l'État. Un concept absolutiste et ses origines médiévales (bas Moyen Âge)», trad. fr. par L. Mayali, dans Id., Mourir pour la patrie, Paris, Fayard, 1984, p.75-103 ( $1^{\text {ère }}$ éd. : New York, 1965).

MONIER, Frédéric, «Le secret en politique, une histoire à écrire », Matériaux pour l'histoire de notre temps, 58 (2000), p. 3-8.

SimonetTA, Marcello, Rinascimento segreto. Il mondo del segretario da Petrarca a Machiavelli, Milan, 2004.

SiMmEL, Georg, Secret et sociétés secrètes, trad. fr., Strasbourg, Circé, 1991.

ZERBA, Michelle, «The frauds of Humanism : Cicero, Machiavelli, and the Rhetoric of Imposture », Rhetorica, 22:3 (hiver 2004), p. 215-240.

\section{Le for intérieur, entre l'individu et l'institution}

CARbasse, J-M., «La place du secret dans l'ancien procès pénal », dans JeanPierre ROYER et Bernard DURAND (dir.), Secret et justice: le secret entre éthique et technique? Actes du Colloque 3-4-5 décembre 1998, Faculté des sciences juridiques, politiques et sociales de Lille, organisé par le Centre d'histoire judiciaire de Lille, Lille, Centre d'histoire judiciaire, 2000.

Chiffoleau, Jacques, «Dire l'indicible. Remarques sur la catégorie du nefandum du XII ${ }^{\mathrm{e}}$ au XV $\mathrm{XV}^{\mathrm{e}}$ siècle », Annales E.S.C., (mars-avril 1990), p. 289324. 
CouËTOuX, Michel, La Justice et les fonctions sociales du secret : rapport général et conclusions, Paris, La Documentation française, 1981.

KUTtNer, Stephan «Ecclesia de occultis non iudicat», Acta Congressus iuridici internationalis (Rome, 12-17 nov. 1934), vol. III, Rome, 1936, p. 225246.

L'Aveu: Antiquité et Moyen-Age, Actes de la table ronde organisée par l'Ecole française de Rome avec le concours du CNRS et de l'Université de Trieste, Rome, 28-30 mars 1984, Rome, École française de Rome, 1986.

PRODI, Paolo, Una storia della giustizia. Dal pluralismo dei fori al moderno dualismo tra coscienza e diritto, Bologne, Il Mulino, 2000.

THERY, Julien, «Fama. L'opinion publique comme preuve judiciaire. Aperçu sur la révolution médiévale de l'inquisitoire (XII-XIVe siècle) », dans Bruno LEMESLE (dir.), La Preuve en justice de l'Antiquité à nos jours, Rennes, PUR, 2003, p. 119-147.

Von Moos, Peter, "Occulta cordis. Contrôle de soi et confession au Moyen Âge », Médiévales, 29 (1995), p. 131-140 et 30 (1996), p. 117-137.

- «Das Öffentliche und das Private im Mittelalter. Für einen kontrollierten Anachronismus », in Das Öffentliche und das Private in der Vormoderne, Gert Melville et Peter von Moos (dir.), Cologne, Böhlau Verlag, 1998, p. 386.

- " "Public" et "Privé" à la fin du Moyen Âge. Le "bien commun" et la "loi de la conscience" », Studi medievali, 41, 2 (2000), p. 505-548.

- Entre histoire et littérature. Communication et culture au Moyen Âge, Florence, Edizioni del Galluzzo, 2005. 